\title{
ACCESSIBILITY AS A COVERAGE BENEFIT ANALYSIS TOOL THAT AN AIRPORT CAN PROVIDE TO A REGION. CASE STUDY: COLOMBIAN COFFEE CULTURAL LANDSCAPE
}

\author{
Diego Alexander ESCOBAR* \\ Universidad Nacional de Colombia, Facultad de Ingeniería y Arquitectura, Departamento de Ingeniería Civil, \\ Grupo de Investigación en Movilidad Sostenible (GIMS), Career 37 Street 94, CP 170003, Manizales, Colombia, e-mail: daescobarga@ unal.edu.co

\section{Santiago CARDONA} \\ Universidad Nacional de Colombia, Facultad de Ingeniería y Arquitectura, Departamento de Ingeniería Civil, \\ Grupo de Investigación en Movilidad Sostenible (GIMS), Career 37 Street 94, CP 170003, Manizales, Colombia, e-mail: scardonau @unal.edu.co
}

\section{Carlos Alberto MONCADA}

Universidad Nacional de Colombia, Facultad de Ingeniería, Departamento de Ingeniería Civil y Agrícola,

Programa de Investigación en Transporte (PIT), Career 35 Street 26, CP 111321, Bogotá, Colombia, e-mail: camoncadaa@unal.edu.co

Citation: Escobar, D.A., Cardona, S., \& Moncada, C.A. (2020). ACCESSIBILITY AS A COVERAGE BENEFIT ANALYSIS TOOL THAT AN AIRPORT CAN PROVIDE TO A REGION. CASE STUDY: COLOMBIAN COFFEE CULTURAL LANDSCAPE. GeoJournal of Tourism and Geosites, 31(3), 1092-1102. https://doi.org/10.30892/gtg.31322-545

\begin{abstract}
In 2011, UNESCO declared the Colombian Coffee Cultural Landscape (CCL) as a world heritage region. In this research article, we propose a methodology to evaluate the geographic location of a new airport (Coffee Airport in Palestina, Caldas), planned as a push of economic development of CCL. We calculate its benefits in terms of population and tourist equipment coverage through accessibility models. Geostatistical methods are used to construct the curves to complement accessibility measures. The results showed that Coffee Airport produces savings in $16 \%$ of travel time and an increase in $1 \%$ in accessibility to the tourist points of the CCL.
\end{abstract}

Key words: Tourism, Airports, Integral Accessibility, Potential Accessibility, Coffee Cultural Landscape, Geostatistics, Transport.

\section{INTRODUCTION}

Global passenger air transport has developed exponentially, mobilizing a total of 4,233 million people in 2018, a value 13.6 times larger than the one from 1970 (World Bank, 2019). As can be seen in Figure 1, China and the United States were the countries that recorded the most air passenger traffic, while European countries, Australia, and Brazil in South America follow them in the scale. In this sense, Colombia generated about 34 million passengers in 2018, 11.2 times higher than registered in 1970 (Civil Aeronautics of Colombia, 2019; World Bank, 2019).

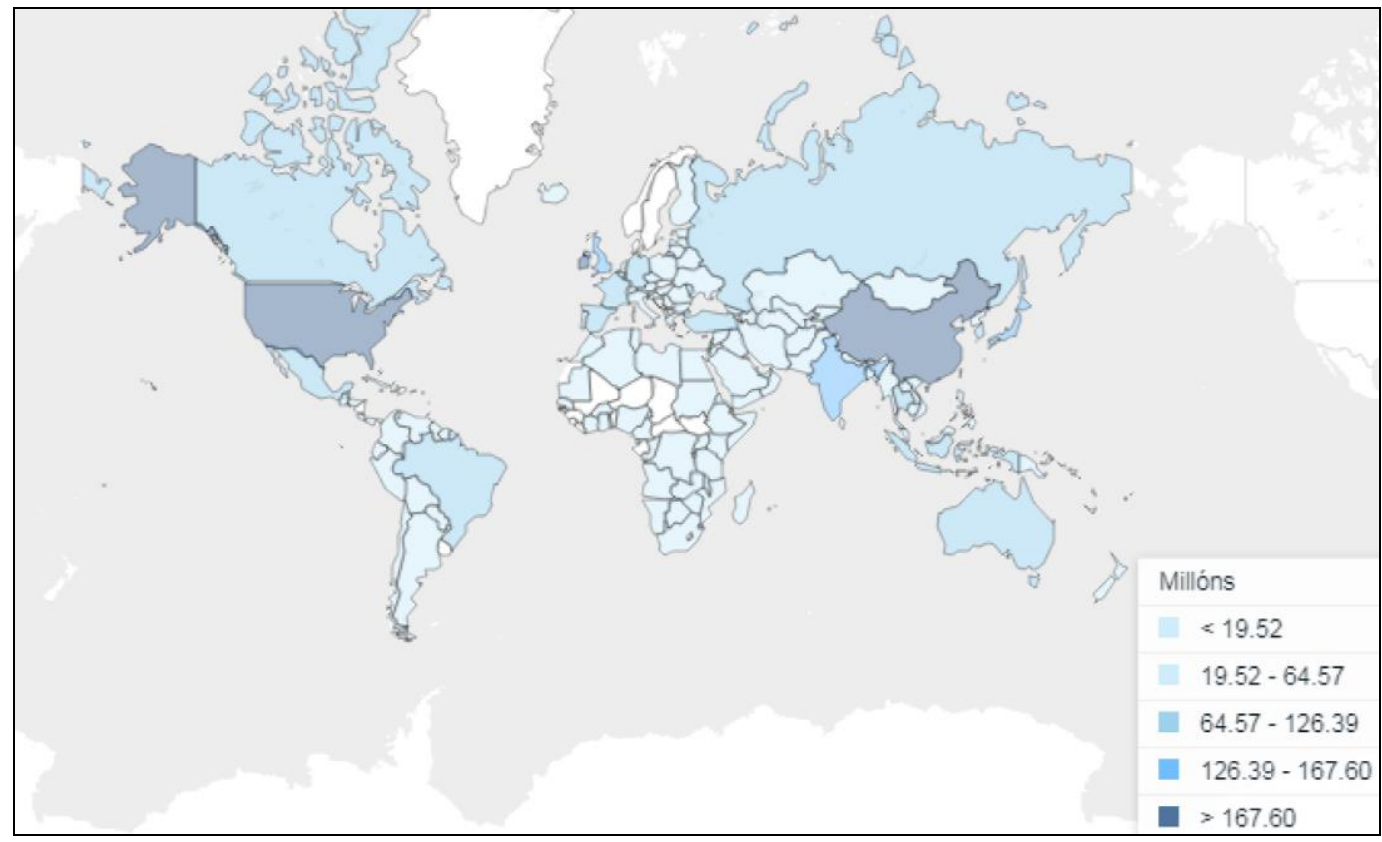

Figure 1. Global air traffic passengers by country (Source: World Bank Data, 2019)

The growth of global air traffic has been fundamental for the development of tourism generating a mutual dependence where tourist destinations are responsible for the development of the airport and route supply, and airlines are involved in the planning and continuous

\footnotetext{
${ }^{*}$ Corresponding author
} 
improvement of the tourist destinations (Duval, 2013; Lohmann and Vianna, 2016; Sharpley, 2008; Spasojevic et al., 2018). According to the World Tourism Organization (UNWTO), 56\% of the world's air traffic aims at holidays and recreation, and 58\% of people prefer aircraft as a means of transport when it comes to sightseeing, which means that the export of passengers that aim for tourism is the third most important category of exports worldwide, producing in 2017 about 1.5 billion dollars (UNWTO, 2019).

Colombia has followed global dynamics, generating as many as 54.3 million passengers in domestic air traffic in 2018 and receiving nearly 14.9 million passengers in international air traffic. In terms of tourism for 2014, in Colombia 20 million passengers were mobilized within the national air traffic and 5 million passengers through international air traffic, which placed this item as the third-highest contributor of the country's gross domestic product (GDP) (Olariaga et al., 2016). With this in mind, the coffee region of Colombia has promoted tourism in its region through the Coffee Cultural Landscape (CCL), which was declared a World Heritage Site by UNESCO in 2011, so its protection and management is imperative from an environmental, economic and social sustainability perspective (Cárdenas et al., 2016; Ramírez and Saldarriaga, 2014; UNESCO, 2011). The CCL joins the departments of Caldas, Risaralda, Quindío, and the northern Valle del Cauca area (Figure 2) seeking to highlight the combination of work between man and nature and generating strategies of promotion based on four pillars, as Cárdenas Martínez and Buitrago Marques (2016) state "living great adventures in exclusive places, enjoying nature and unique landscapes, learning about authentic trades in the region and enjoying the culture of the best coffee in the world" (pp. 45-46).

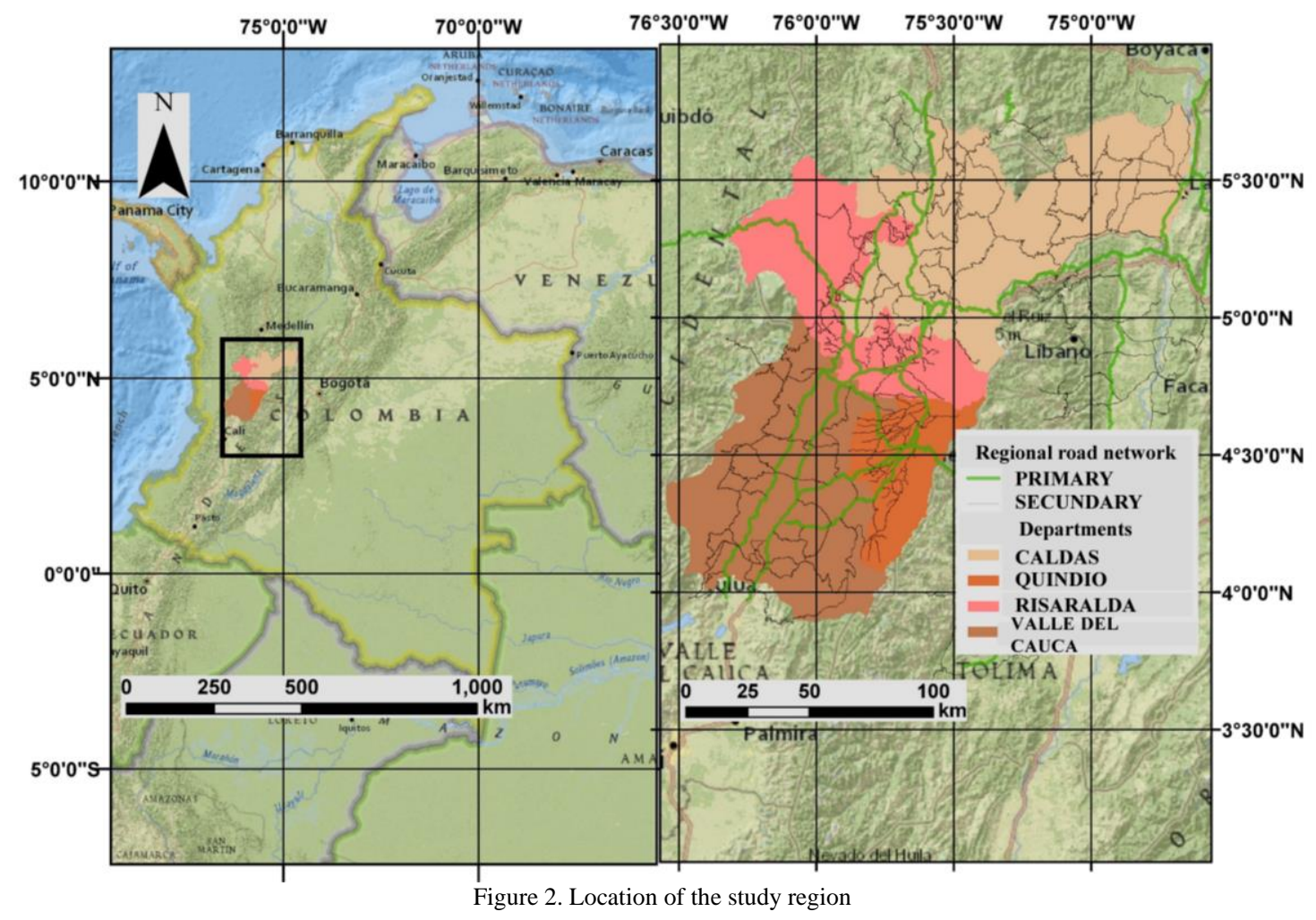

With the view on the mutual relationship between tourist destinations and air traffic, since 2004 the Colombian government has declared the strategic importance of building an airport in a region that has about 3 million inhabitants, located in the municipality of Palestina in the department of Caldas, to complement the operation of the airports Matecaña (located in the city of Pereira in the department of Risaralda) and El Edén (located in the city of Armenia in the Quindío department), and to replace the low operation of airport La Nubia in Manizales, capital of the department of Caldas (Conpes, 2004). The airport of Palestina has been constantly related to the boost of the CCL and the economy of the coffee region so its general connotation has been that of Coffee Airport, however, its construction has been delayed 15 years since its beginning in 2005, generating cost overruns that have produced divided opinions in the national government regarding support for this large infrastructure work (Conpes, 2009; Coffee Airport, 2019).

This research proposes a methodology that evaluates the geospatial location of an airport and its relationship with tourism in the region through the measurement of integral accessibility and potential accessibility of tourism's equipment and population. In this case study, the measurement is performed for each airport in the coffee region (La Nubia, El Edén, Matecaña) in order to calculate their current coverage. Afterward, the measurement of the future scenario is made, including the Coffee Airport and comparisons between the analysis scenarios and their connection with the tourist offer of the CCL. In the last case, where relationships between the location of airports and tourist points are calculated, the main factor is that transit time is seen as a friction factor and an attraction is usually modeled by the Distance Decay functions, where demand for activities decreases as the distance traveled, time, cost, or effort increases (Paulino et al., 2019).

Accessibility is the potential for interaction opportunities held by a person assessed considering urban facilities, the supply of road infrastructure, and different modes of transport that can be used by people in a region (Geurs and Ritsema van Eck, 2001; Hansen, 1959; Miller, 2018). The potential accessibility, proposed by Hansen (1959), is a measure that considers the different uses of land and the location of the range of facilities in the space, which can be accessed through the road infrastructure added to the desire of people to move around (Vale and Pereira, 2016). This measure has been widely used and developed over the years in various topics such as the study of pedestrian accessibility (Vale and Pereira, 2016), access to health (Eva and Iatu, 2015), airports (Reynolds-Feighan and McLay, 2006) and tourism (Harb and Bassil, 2020). In this same sense, geographical accessibility is an infrastructure-based measure as it is evaluated through the travel times offered by the road network under study (Geurs and Ritsema van Eck, 2001). Relative accessibility is a measure between two points of the road network in the city (Ingram, 1971), while integral accessibility allows measuring the travel time for the nodes in the road network toward particular points in the city like universities, hospitals, shopping malls, etc. In this case, integral accessibility has active and passive 
assumptions. Passive assumption measures people's accessibility when traveling toward facilities like universities or shopping malls. On the other hand, active assumption measures people accessibility when facilities must travel towards people like police officers, firefighters or ambulances services (Escobar et al., 2019). In this research, integral accessibility will be used to measure the coverage offered by the airports through the road network, generating the isochronous of travel time accessibility which can be analyzed together with the population and tourism offer in the region (Xi et al., 2018). This measure, as the potential accessibility, has been widely used by researchers in public transport issues (Escobar et al., 2015), regional accessibility (Zuluaga and Escobar, 2017), health offer (Holguin et al., 2018), among others.

This research methodology contributes to the measuring accessibility topic because it implements the use of geostatistical me thods to build the isochronous curves of travel time coverage. Besides, accessibility measures have not been extensively used in the calculation of tourist supply in a region and even in the evaluation of the geographical location of a new airport and its tourist and popul ation coverage in the region. On the other hand, this methodology contributed to the conservation, protection, and boosting of the world heritage CCL declared by UNESCO and it could be applied in similar areas around the world to boost their conservation and protection. The research methodology followed by the main results and a discussion around them will be presented below. Finally, it concludes on the subject studied.

\section{MATERIAL AND METHODS}

The research methodology (Figure 3) consists of six consecutive stages, which are described below. It should be mentioned that the flowchart of the methodology is adapted to the case study, however, it can be replicated in any similar study, if having the tools described in accordance.

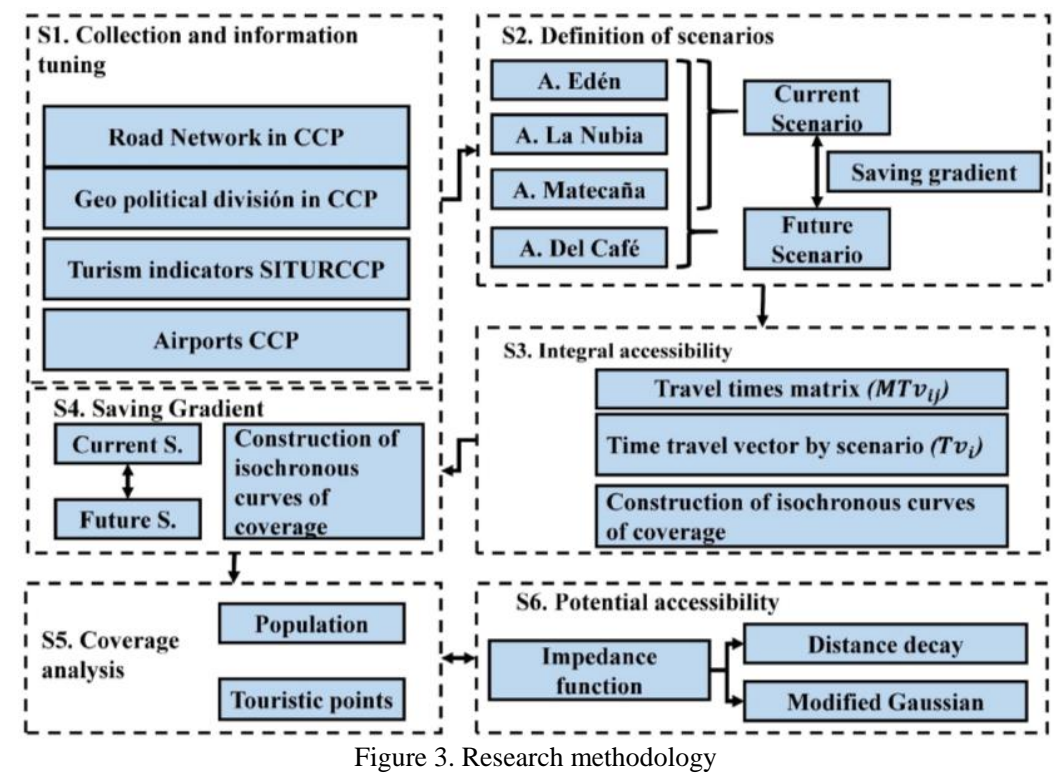

Collection and information tuning: The basic information needed to carry out this research is composed of four basic layers. First, it is necessary to take into account the road network of the airport's impact area, it must comply with certain connecting characteristics according to the graph theory, which generally tells us that the transport networks are composed of arches (roads) and nodes (road intersections) (Kozyrev, 1972; Segui and Petrus, 1991; Xiao, 2016) and possess minimal attributes of length, speed and travel time. In this case, the layer of the regional road network in GIS format "shape", composed of primary and secondary roads, was obtained from preliminary research carried out in the area of study (Zuluaga and Escobar, 2017) and updated according to the regional network layer of the Colombian departments downloaded from the National Geostatistical Framework (NGF) of the National Administrative Department of Statistics (DANE as its acronym in Spanish) (DANE, 2019). The length is calculated using the "Calculate Geometry" tool in the ArcGis software, the speed attribute was defined at $51 \mathrm{~km} / \mathrm{h}$ for the primary roads and $34 \mathrm{~km} / \mathrm{h}$ for the secondary roads according to Zuluaga and Escobar (2017) that took into account the maximum and functional speeds of the region. Finally, the travel time is calculated by relating the defined length and speed.

Second, the polygon layer in the study area is defined, with minimal population and area attributes, which is critical for the construction of coverage isochronous and the analysis of results from subsequent stages. In our case, the municipalities belonging to the coffee region, discharged from the NGF and the area declared as the main and buffering area of the coffee cultural landscape (CCL), provided by the Ministry of Culture, will be considered. For the updating of the population by the municipality, the results of the census population adjusted for coverage and percentages of national and departmental omission by area of the National Census of Popu lation and Housing (CNPV as its acronym in Spanish) 2018 of DANE (DANE, 2019) were considered. Thirdly, the tourism indicators in the area of influence of the CCL. For this case, the tourism indicators with the job offer, recipient tourism, internal, emitter, and sustainable CCL were downloaded, which are available in KMZ format in the tourist information system of the Coffee Cultural Landscape (SITURCCL, 2019). This format allows the georeferencing of the points including various attributes such as name, department, municipality, address, category, and subcategory, among others.

Finally, the airport to be studied is georeferenced and the airports with which it will be compared, if applicable. For our study, the location layer of the operating airports in the study area (La Nubia, Matecaña, El Edén) and the Coffee Airport is built, georeferencing them in ArcGis using latitude and longitude coordinate attributes obtained through GoogleMaps.

Definition of scenarios: The projected airport and the airports in the study area that are in operation must be considered for the definition of scenarios. In this case study, to quantify the coverage of each airport, the integral accessibility to the operating and projected airports (A. Edén, A. La Nubia, A. Matecaña, and A. Coffee) shall be measured. Secondly, to measure the current and future coverage offered by airports in the region, a measurement of integral accessibility will be made considering the operating airports for the current situation and including the Coffee Airport for the future situation. The last scenario relates to the current and future integral accessibility of the study area through the savings gradient. In the end, scenarios will be used to measure the potential accessibility to tourist points. 
Integral accessibility: Three sub-stages which are described below, will be carried out for this calculation:

$$
\text { (1) Travel times matrix }\left(\mathrm{MTV}_{\mathrm{ij}}\right) \text { : }
$$

Taking into account the road network layer and the location of the airports under study, we proceed to calculate the travel time that takes each node of the road network (i) to reach the airports under study (j) (Escobar et al., 2019). For the calculation of travel times, the Dijkstra shortest path algorithm (1959) is considered, which optimizes travel time between two points of the road network considering the turn penalties (Caldwell, 1961), determined in the region in 34 seconds on the left and 29 seconds on the right by Cardona (2018). This process is carried out in the TRANSCAD 8.0 software, which has transport modelling tools providing speed in the analysis of optimization of the routes to be calculated in the 29001 nodes of the studied regional road network. Also, this software allows implementing the turn penalties globally, because its node-to-node inclusion does not provide greater precision to the analysis (Yiannakoulias et al., 2013).

\section{(2) Time vector by scenario $\left(\mathrm{TV}_{\mathrm{i}}\right)$ :}

Considering the travel time matrix, we proceed to obtain the travel time vector for each scenario defined in the previous stage. In the case of each airport, the vector of 29001 where the minimum travel time that takes each node of the regional road network to reach each airport is obtained. On the other hand, to calculate the coverage offered by airports in the region, the minimum travel time of each node studied to the airports must be obtained, that is, for each node studied, we only take into account the nearest airport in terms of travel time and that in terms of accessibility this would be your optimal option to access.

\section{(3) Construction of isochronous curves of coverage:}

For this stage of integral accessibility, the travel time vectors of each scenario are related to their respective geographical coordinates. Then, considering the travel time of each node, the coverage curves of each scenario are constructed using the geostatistical method of ordinary kriging interpolation which relates the observed values according to their distance, using the linear semi-variogram to predict unknown travel time values in the study region (Chun and Griffith, 2013; Xiao, 2016). This method has been recognized as the optimist interpolator and has been used in recent decades by researchers and consultants in the transport area to perform geostatistical analyses on issues related to public transport (Zhang and Wang, 2014), coverage of facilities such as fire stations (Escobar et al., 2019) and emergency services (Holguin et al., 2018), among others.

Savings gradient (GA \%): Two sub-stages will be carried out to obtain the savings gradient. The first of these compares the travel time vector between the scenarios studied in such a way that the time difference is obtained in terms of percentage (equation 1) (Cardona et al., 2018).

$$
G A \%=\left(\frac{T V 1-T V 2}{T V 1}\right) * 100(1, \text { source Cardona et al. }(2018)
$$

Where TV1 represents the average travel time vector of the current scenario of airport operation in the region and TV2 represents the average travel time vector of the future scenario of airport operation in the region with the start-up of the Coffee Airport. After obtaining the vector where the gradient of savings is reflected, it is relating to the coordinates of each node, and the isochronous curves of savings coverage are constructed using the ordinary kriging geostatistical model with linear semi-variogram as described in the third sub-stage of integral accessibility.

Coverage analysis: After the construction of the isochronous curves of integral accessibility and savings gradient for the different scenarios, we proceed to perform the analysis of coverage and spatial interaction offered by airports and different scenarios studied to the population and points of tourist interest; in this case, those offered in the CCL (PITPCC) according to the SITURPCC. Two aspects will be considered in this analysis. The first, is a full population coverage analysis, and the second, considering the PITPCC number (Rodrigue et al., 2013).

Potential accessibility: For its calculation, the general formula proposed by Hansen (1959) (equation 2) where the range of equipment $(O)$ and an impedance function based on travel time or distance $f(T v i)$ (Echenique et al., 1969) is taken into account (Hansen, 1959; Salze et al., 2011; Vale and Pereira, 2016).

$$
A P i=O i * f(T v i)(2, \text { source Hansen(1959) }
$$

Where $O i$ represents the opportunities in a region and $f(T v i)$ represents the impedance or friction function based on travel time or distance.

The range of equipment will be drawn from the coverage that each scenario offers to the PITPCCs, obtaining the number of points for each isochronous accessibility curve (Oi). In the same way, the impedance functions are responsible for mitigating accessibility as travel time increases, decreasing the willingness of travel (Halás et al., 2014; Martinez and Viegas, 2013). This article will consider the distance decay function (Ingram, 1971; Pulino et al., 2019; Vale and Pereira, 2016) and the modified Gaussian function (Salze et al., 2011).

For the distance decay function (equation 3 ) the deterrence factor $(\beta)$, which defines the willingness to travel by users, according to the mode of transport and the reason for the trip using the data from the source-destination matrix of the study region (Olsson, 2016; Salze et al., 2011; Taylor, 1975). However, in this case, this data is not accessed so the deterrence factor will be chosen from a constructed sensitivity curve varying in value from 0.01 to 0.15 , values extracted as common in the studied literature (Echenique et al., 1969; Halás et al., 2014; Hansen, 1959; New Zeland Transport Agency, 2013; Olsson, 2016; Vale and Pereira, 2016). This parameter is inversely proportional so that as its value is lower, the greater the desire of people to make the trip.

$$
f(T v i)=100 * e^{\left(-\beta * T v_{i}\right)} \quad(3, \text { source Echenique (1969) }
$$

Where $f(T v i)$ represents the impedance or friction function, $T v i$ as travel time or distance and $(\beta)$, is the deterrence factor which defines the willingness to travel by users. 
For the modified Gaussian function (equation 4) the $v$ factor is calculated which is a measure of the dispersion of travel times from the travel time vector of each of the studied scenarios. This is calculated as the average of the raised travel time vector squared (equation 4) (Ingram, 1971).

$$
\left.f(T v i)=100 * e^{\left(-\frac{T v i^{2}}{v}\right)} \text { (4,source Ingram(1971). } \quad v=\sum_{n}^{\sum T v i}\right)^{2} \quad(5, \text { source } \operatorname{Ingram}(1971)
$$

Where $f(T v i)$ represents the impedance or friction function, $T v i$ as travel time or distance, $v$ is the dispersion of travel times and $n$ are the total nodes in the travel time vector.

\section{Results and Discussion}

First, in Figure 4 the four layers of data are presented, an input for the achievement of this study. The regional road network consists of 7 $259 \mathrm{~km}$ of roads of which $1686 \mathrm{~km}(23 \%)$ are primary roads and 5,573 km (77\%) correspond to secondary roads. On the other hand, the studied area consists of 76 municipalities distributed in 4 departments: Caldas (27 municipalities), Risaralda (14 municipalities), Quindío (12 municipalities), and the north region of Valle del Cauca (23 municipalities). Table 1 provides a summary of the data collected in the studied area, including the population, area, and number of touristic points of the Coffee Cultural Landscape (PITPCC) located within it, according to the SITURPCC census (2019).

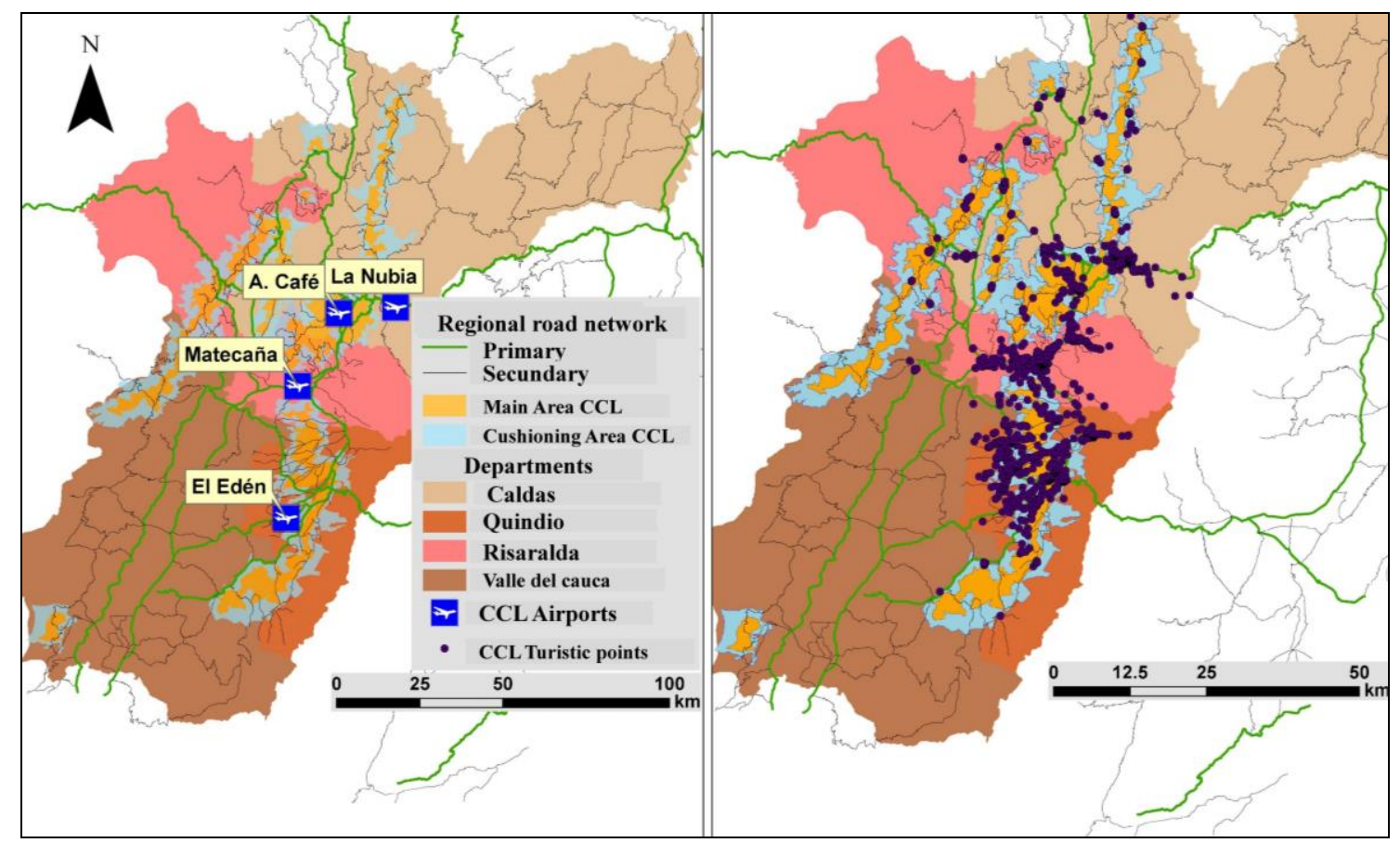

Figure 4. Layers of data used in research

Table 1. Summary of data by department

\begin{tabular}{|l|c|c|c|}
\hline Department & Population & Area (ha) & Touristic points \\
\hline Caldas & 993866 & $741.25,98$ & 583 \\
\hline Risaralda & 967767 & 397601,1 & 827 \\
\hline Quindío & 575010 & 193489,57 & 1034 \\
\hline North Valle del Cauca & 764491 & 635123,79 & 29 \\
\hline Total & 3301134 & 1968140,44 & 2473 \\
\hline CCL main area & 248964 & 140794,94 & 396 \\
\hline CCL cushioning area & 451081 & 206474,7 & 404 \\
\hline Total & 700045 & 347269,64 & 800 \\
\hline
\end{tabular}

In this case, it should be noted that the department of Quindío, despite being the one that has the lowest population and the lowest area among the departments in the study, has the most touristic points with 1 034. In contrast, the department of Caldas, although it has the highest population and area values, its number of touristic sites are located below departments such as Quindío and Risaralda. Finally, the north of the Valle del Cauca is the studied department that has the least touristic sites, considering that a low percentage of the declared and cushioning area of the CCL is in this department. The main area of the CCL, declared by the Colombian Ministry of Culture, reaches 248964 inhabitants, representing $7.5 \%$ of the total population of the studied area. On the other hand, it is declared a buffering area for the CCL which surrounds the main area and has 451081 inhabitants. In total, the sum of these areas declared by the Ministry of Culture, cover 56 municipalities in the four departments of the studied area, which equates that the 800 touristic points of the CCL are located within the main and cushioning area of the CCL.

Finally, within the studied area are three airports (El Edén, La Nubia, and Matecaña) which carried 2413766 passengers in 2018, representing 3.4\% of the total passengers mobilized in Colombia for this year (Civil Aeronautics of Colombia, 2019). The Matecaña airport, located in Pereira, the capital of the department of Risaralda, is the most important airport in the studied area because it transports $74.3 \%$ of the total passengers mobilized from the studied area through 5 national and 4 international routes, of which 3 are through connections (Matecaña Airport, 2019). Likewise, the airport El Edén, located in Armenia, capital of the department of Quindío, mobilized in 2018, 396 110 passengers (16.4\% of the total) through 2 national destinations (with the projection of opening 1 more at the end of 2019) and 1 international. The airport La Nubia, located in Manizales, capital of the department of Caldas, mobilized in $20189.3 \%$ of the total passengers 
of the studied area, having in operation 2 national routes, widely limited by the length of the runway and the weather characteristics of the city (Conpes, 2009). Finally, the Coffee Airport, which is under construction, is in the municipality of Palestina and has a projected airport capacity of about 1.8 million passengers by 2030 and just over 3 million by 2050 (Coffee Airport, 2017).

\section{Integral accessibility and saving gradient}

On the left side of Figure 5, we can see the isochronous curves of integral accessibility of the current situation of the CCL airports. In addition, Table 2 shows all the results for the different scenarios of the integral accessibility studied, among which are La Nubia Airport, which generates a total coverage of the population in 360 minutes or less, while that El Edén Airport has the maximum travel time with 465 minutes. In this case, Matecaña Airport has a total population coverage for times less than 405 minutes, while the Coffee Airport would generate a total coverage in less than 375 minutes, just 15 minutes more than La Nubia airport.

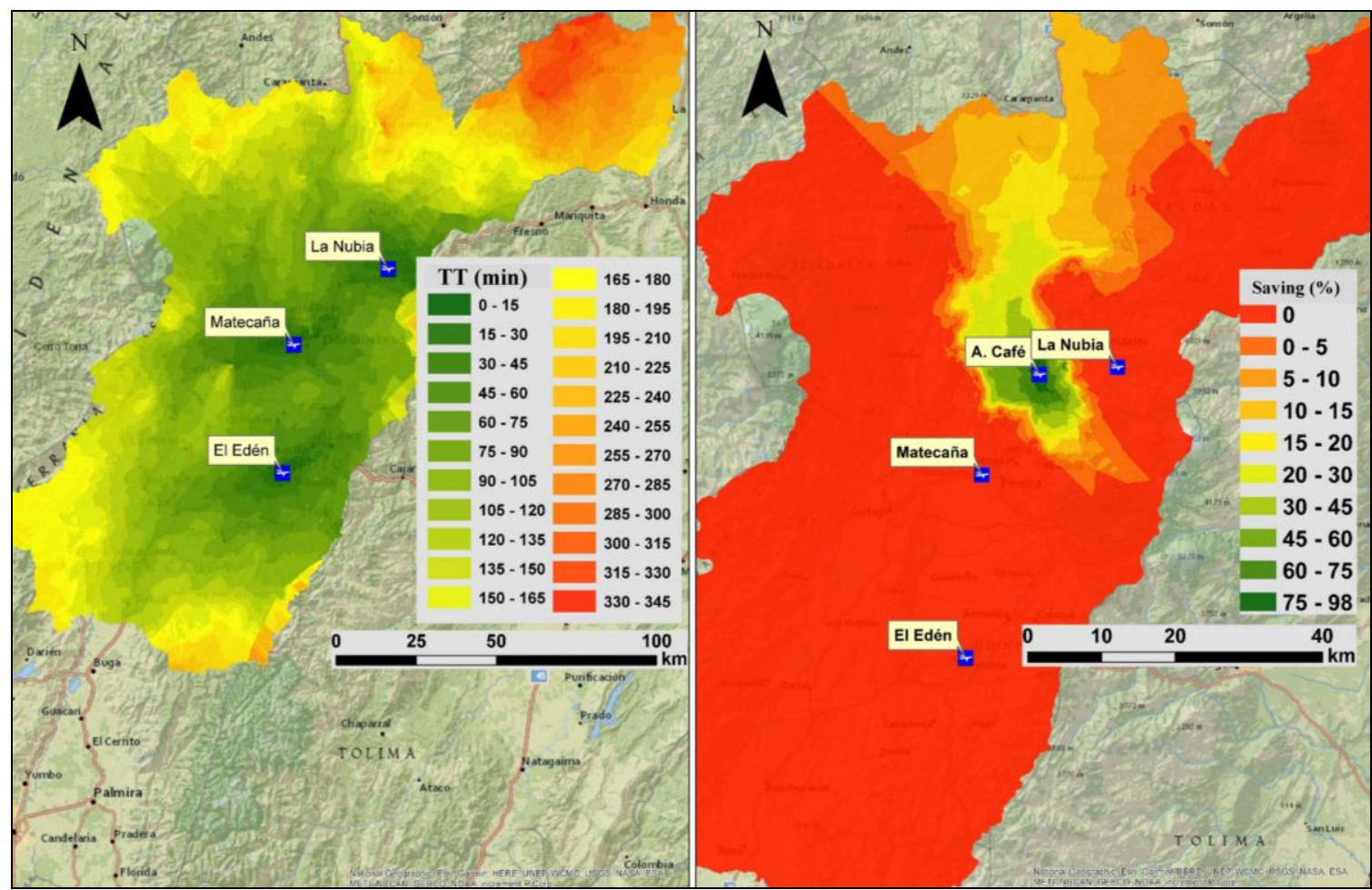

Figure 5. Integral accessibility, current scenario (left side). Savings gradient (right part)

Table 2. Population coverage according to travel time

\begin{tabular}{|c|c|c|c|}
\hline Category & Sub-category & Points & Percentage \\
\hline \multirow{3}{*}{ Travel agencies } & Wholesale travel agencies & 17 & $0,69 \%$ \\
\hline & Operator travel agencies & 251 & $10,15 \%$ \\
\hline & travel and tourism operators & 200 & $8,09 \%$ \\
\hline \multicolumn{2}{|c|}{ Car rental companies for national and international tourism } & 14 & $0,57 \%$ \\
\hline \multicolumn{2}{|l|}{ Park service concessionaries } & 1 & $0,04 \%$ \\
\hline \multirow{3}{*}{ Timeshare companies } & marketing companies & 2 & $0,08 \%$ \\
\hline & development companies & 1 & $0,04 \%$ \\
\hline & marketing and development companies & 1 & $0,04 \%$ \\
\hline \multirow{2}{*}{ Automotive land transport companies } & "Chivas" companies & 1 & $0,04 \%$ \\
\hline & Special automotive land transport & 29 & $1,17 \%$ \\
\hline \multicolumn{2}{|c|}{ Savings companies for travel and tourism services } & 1 & $0,04 \%$ \\
\hline \multirow{9}{*}{ Accommodation and lodging facilities } & shelter & 5 & $0,20 \%$ \\
\hline & rural housing & 692 & $27,98 \%$ \\
\hline & apart-hotel & 131 & $5,30 \%$ \\
\hline & camping & 6 & $0,24 \%$ \\
\hline & vacation center & 12 & $0,49 \%$ \\
\hline & hostel & 213 & $8,61 \%$ \\
\hline & hotel & 606 & $24,50 \%$ \\
\hline & hut & 2 & $0,08 \%$ \\
\hline & touristic house & 55 & $2,22 \%$ \\
\hline \multirow{3}{*}{ Gastronomy establishments } & bar & 4 & $0,16 \%$ \\
\hline & restaurant & 8 & $0,32 \%$ \\
\hline & bar y restaurant & 44 & $1,78 \%$ \\
\hline \multicolumn{2}{|l|}{ Tourist guide } & 93 & $3,76 \%$ \\
\hline \multicolumn{2}{|l|}{ Touristic representation office } & 38 & $1,54 \%$ \\
\hline \multicolumn{2}{|c|}{ Professional operators of fairs, congress and conventions } & 37 & $1,50 \%$ \\
\hline \multicolumn{2}{|c|}{ Theme parks } & 8 & $0,32 \%$ \\
\hline \multirow{2}{*}{\multicolumn{2}{|c|}{$\begin{array}{l}\text { Users operators, developers and industrials in tourist free zones } \\
\text { Total }\end{array}$}} & 1 & $0,04 \%$ \\
\hline & & 2473 & $100,00 \%$ \\
\hline
\end{tabular}


On the right side of Figure 5, you can see the isochronous curves of saving gradient (\%) where travel times are compared between the current and future scenarios. The start-up of the Coffee Airport generates savings of up to 5\% in about 480 thousand inhabitants of the studied area (Figure 6). Besides, most of these people live in the department of Caldas and Risaralda. On the other hand, savings in travel time gradually grow to reach maximums of $98 \%$ savings, for the inhabitants of the municipality of Palestina, where the airport is being built. This project generates proven benefits in terms of travel time to the inhabitants of the studied area, which gives them greater access to the opportunities generated by the presence of an international airport (air and cargo traffic) with operational capacitie s greater than those currently operating in the area (Conpes, 2009).

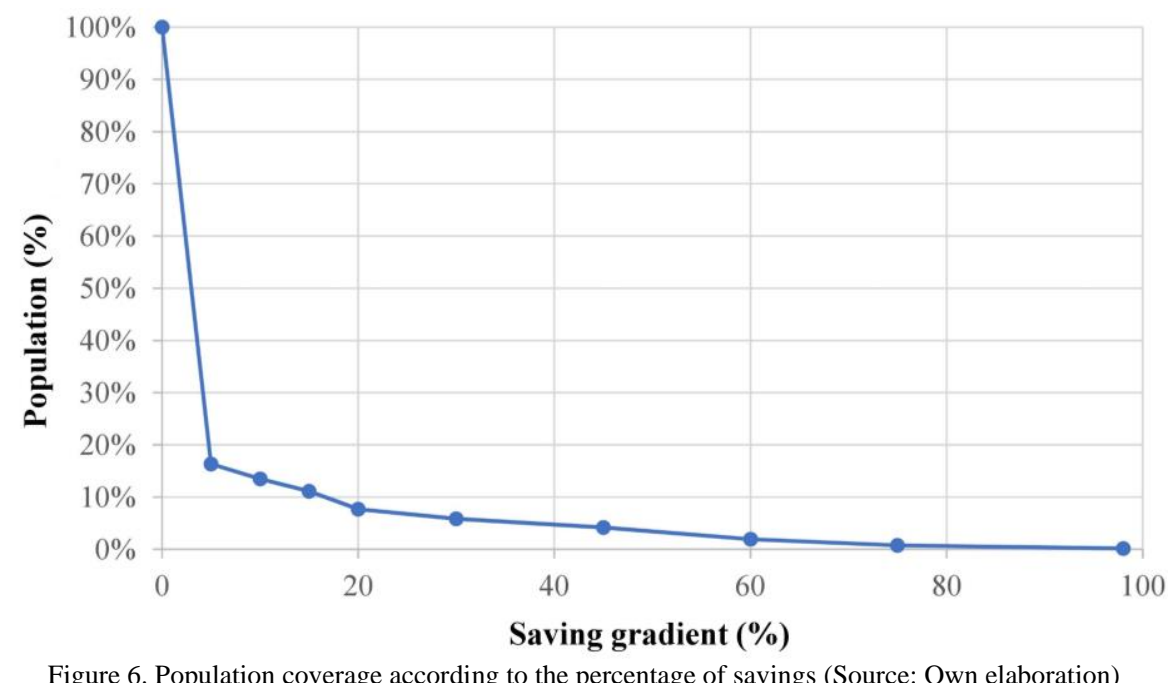

\section{Coverage analysis}

The full coverage analysis is presented in Figure 7 considering population (top) and PITPCC (bottom).
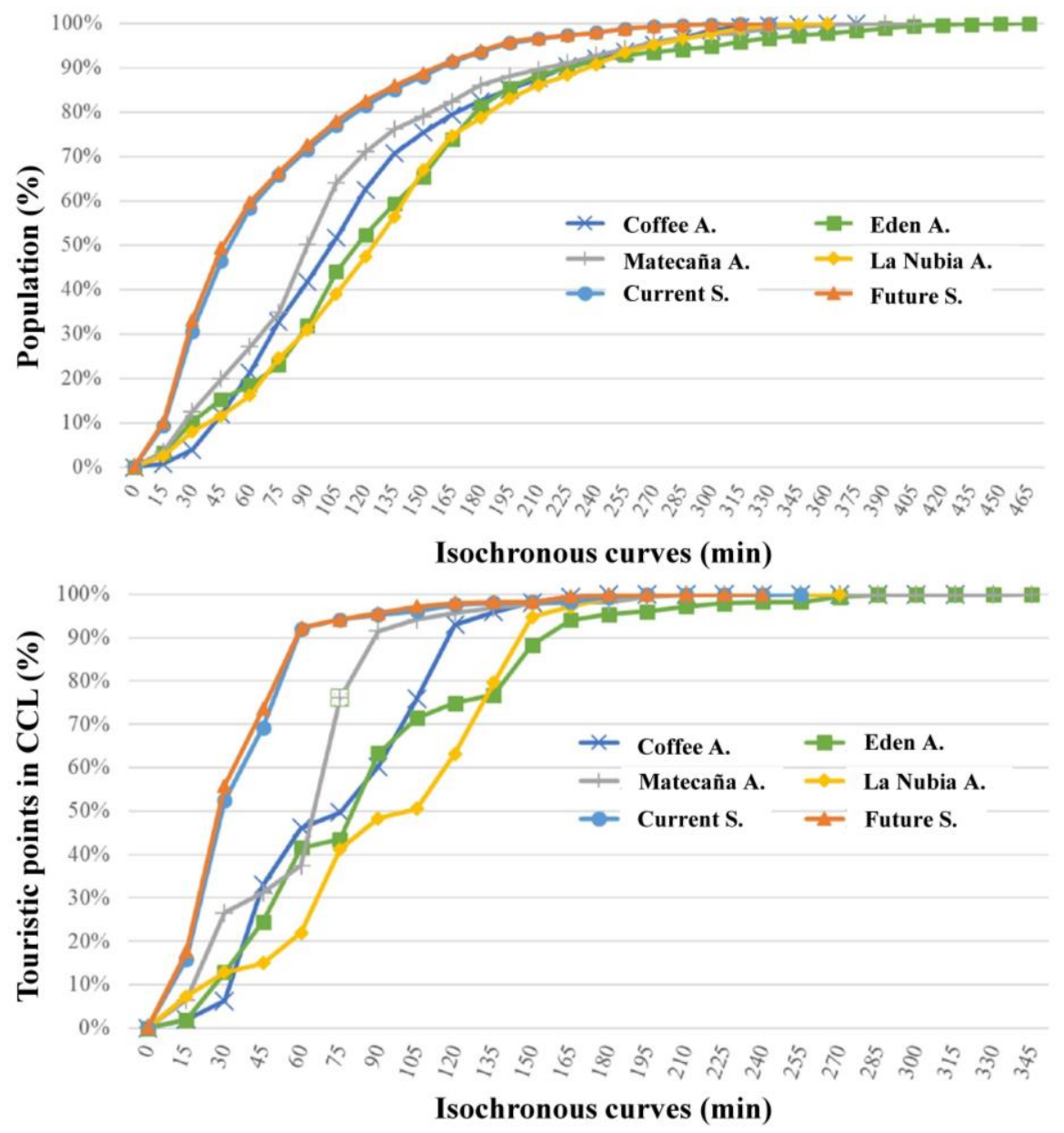

Figure 7. Population coverage (top) and PITPCC (bottom) analisys

It highlights that better coverage is generated as the curve of the scenarios is higher, indicating greater population coverage or PITPCC in shorter average travel time. In the population coverage of each of the scenarios, it is observed that the future scenario generates an 
improvement in the conditions of coverage of the population when the Coffee Airport starts operating in comparison to the current form of the geospatial location of the airports. Nonetheless, the Matecaña Airport generates greater coverage to the population since about $50 \%$ of it (Table 3), accesses in times less than 90 minutes while the Coffee Airport reaches a coverage of $42 \%$ of the population at the same time.

For the other airports to have a population coverage of 50\%, the users' travel times increase in relation to Matecaña Airport by 15 minutes to Coffee Airport, 30 minutes to The Edén Airport, and 45 minutes for La Nubia Airport. In addition, Matecaña Airport generates a more suitable general coverage for the PITPCCs studied since, for times of less than 90 minutes, it reaches a coverage of 91.59\% (2265 PITPCC), while the Coffee Airport and El Edén Airport covers percentages of 60.21\% (1489 PITPCC) and 63.28\% (PITPCC), respectively. Finally, the airport La Nubia achieves coverage percentages less than 50\% with 1195 PITPCC being the equipment that provides the least access in touristic terms.

Table 3. Population coverage by scenario

\begin{tabular}{|c|c|c|c|c|c|c|}
\hline TV (min) & Coffee A. & Eden A. & Matecaña A. & La Nubia A. & Current Scenario & Future Scenario \\
\hline $\mathbf{0}$ & $0,00 \%$ & $0,00 \%$ & $0,05 \%$ & $0,02 \%$ & $0,07 \%$ & $0,07 \%$ \\
\hline 15 & $0,80 \%$ & $3,35 \%$ & $3,43 \%$ & $2,51 \%$ & $9,33 \%$ & $10,13 \%$ \\
\hline 30 & $3,12 \%$ & $6,80 \%$ & $9,08 \%$ & $5,48 \%$ & $21,20 \%$ & $22,94 \%$ \\
\hline 45 & $7,91 \%$ & $5,15 \%$ & $7,36 \%$ & $3,57 \%$ & $15,75 \%$ & $16,20 \%$ \\
\hline 60 & $9,58 \%$ & $3,19 \%$ & $7,27 \%$ & $4,60 \%$ & $12,10 \%$ & $10,53 \%$ \\
\hline 75 & $11,29 \%$ & $4,54 \%$ & $7,62 \%$ & $8,44 \%$ & $7,39 \%$ & $6,65 \%$ \\
\hline 90 & $9,09 \%$ & $8,86 \%$ & $15,33 \%$ & $6,36 \%$ & $5,81 \%$ & $6,18 \%$ \\
\hline 120 & $10,96 \%$ & $8,41 \%$ & $6,98 \%$ & $8,38 \%$ & $4,51 \%$ & $4,56 \%$ \\
\hline 135 & $8,11 \%$ & $6,92 \%$ & $5,03 \%$ & $9,08 \%$ & $3,61 \%$ & $3,43 \%$ \\
\hline 150 & $4,67 \%$ & $6,18 \%$ & $2,92 \%$ & $10,53 \%$ & $2,95 \%$ & $2,85 \%$ \\
\hline 165 & $4,07 \%$ & $8,44 \%$ & $3,27 \%$ & $7,77 \%$ & $3,19 \%$ & $2,85 \%$ \\
\hline 180 & $3,12 \%$ & $7,38 \%$ & $3,74 \%$ & $3,96 \%$ & $2,30 \%$ & $2,17 \%$ \\
\hline 195 & $2,58 \%$ & $4,22 \%$ & $2,05 \%$ & $4,32 \%$ & $2,06 \%$ & $2,01 \%$ \\
\hline 210 & $2,46 \%$ & $2,82 \%$ & $1,46 \%$ & $3,04 \%$ & $0,98 \%$ & $0,76 \%$ \\
\hline 240 & $1,83 \%$ & $1,54 \%$ & $1,78 \%$ & $2,45 \%$ & $0,61 \%$ & $0,60 \%$ \\
\hline 255 & $1,57 \%$ & $1,33 \%$ & $1,38 \%$ & $2,74 \%$ & $0,84 \%$ & $0,84 \%$ \\
\hline 270 & $1,52 \%$ & $0,66 \%$ & $1,67 \%$ & $1,63 \%$ & $0,57 \%$ & $0,57 \%$ \\
\hline 285 & $1,45 \%$ & $0,62 \%$ & $0,81 \%$ & $1,38 \%$ & $0,25 \%$ & $0,25 \%$ \\
\hline 300 & $1,69 \%$ & $0,69 \%$ & $0,75 \%$ & $1,22 \%$ & $0,18 \%$ & $0,18 \%$ \\
\hline 315 & $0,81 \%$ & $1,04 \%$ & $0,51 \%$ & $1,04 \%$ & $0,16 \%$ & $0,16 \%$ \\
\hline 330 & $0,42 \%$ & $0,82 \%$ & $0,85 \%$ & $0,77 \%$ & $0,03 \%$ & $0,03 \%$ \\
\hline 345 & $0,19 \%$ & $0,56 \%$ & $0,54 \%$ & $0,22 \%$ & $0,00 \%$ & $0,00 \%$ \\
\hline 360 & $0,14 \%$ & $0,45 \%$ & $0,26 \%$ & $0,17 \%$ & $0,00 \%$ & $0,00 \%$ \\
\hline 375 & $0,02 \%$ & $0,58 \%$ & $0,18 \%$ & $0,00 \%$ & $0,00 \%$ & $0,00 \%$ \\
\hline 390 & $0,00 \%$ & $0,64 \%$ & $0,15 \%$ & $0,00 \%$ & $0,00 \%$ & $0,00 \%$ \\
\hline 405 & $0,00 \%$ & $0,47 \%$ & $0,03 \%$ & $0,00 \%$ & $0,00 \%$ & $0,00 \%$ \\
\hline 420 & $0,00 \%$ & $0,18 \%$ & $0,00 \%$ & $0,00 \%$ & $0,00 \%$ & $0,00 \%$ \\
\hline 435 & $0,00 \%$ & $0,21 \%$ & $0,00 \%$ & $0,00 \%$ & $0,00 \%$ & $0,00 \%$ \\
\hline 450 & $0,00 \%$ & $0,15 \%$ & $0,00 \%$ & $0,00 \%$ & $0,00 \%$ & $0,00 \%$ \\
\hline 465 & $0,00 \%$ & $0,03 \%$ & $0,00 \%$ & $0,00 \%$ & $0,00 \%$ & $0,00 \%$ \\
\hline
\end{tabular}

\section{Potential accessibility}

First, Figure 8 presents the decay functions used for the calculation of the potential accessibility: (i) the distance decay function, plotting considering deterrence factors between 0.01 and 0.15 (top), and (ii) the modified Gaussian function, plotted by each of the scenarios studied (bottom). The distance decay function quickly drops close to the origin and then stabilizes, resulting in lower travel chances as travel time increases. This behavior happens because the travel times analyzed in this research are high compared to those used it highlights that better coverage is generated as the curve of the scenarios is higher in other research where the scale has been urban (Olsson, 2016; Vale and Pereira, 2016). The sensibility curve constructed with Beta parameters between 0.15 and 0.01 shows an inversely proportional tendency because if parameter Beta increases, travel probability decreases. On the other hand, the behavior of the modified Gaussian function descends in a slightly way close to the origin compared to the distance decay function, allowing the probability of travel to be distributed over the travel times of the studied region. It should be noted that both functions generate similar values for close travel times to the maximum. For the calculation of potential accessibility, the deterrence parameter was de fined at 0.01 given the ratio to the values obtained by the Gaussian function modified in the different scenarios. Finally, it should be noted that the modified Gaussian function does not need assumptions for its calculation, as if it was needed by the distance decay function where it was necessary to propose different deterrence factors, due to the lack of data for its calculation.

Potential accessibility results with distance decay function and deterrence factor of 0.01 are presented in Table 4 . In total terms, the future scenario generates better potential accessibility, $0.963 \%$ better than the current scenario. However, in the case of each airport, Matecaña Airport is the one that generates the best potential accessibility with $46.125 \%$ indication that its location is suitable for the boost of the PITPCCs. On the other hand, Coffee Airport would generate potential accessibility of $40.715 \%$, like the one currently provided by the airport El Edén, which is $38.073 \%$. In the case of La Nubia Airport, its location generates the worst potential accessibility coverage, so its future replacement by the Coffee Airport would be a wise decision. Table 4 also shows the results of the potential accessibility calculated with the modified Gaussian decay function, where there is a considerable difference from the accessibility with distance decay function due to the behavior that each of the decay functions takes close to the origin. 

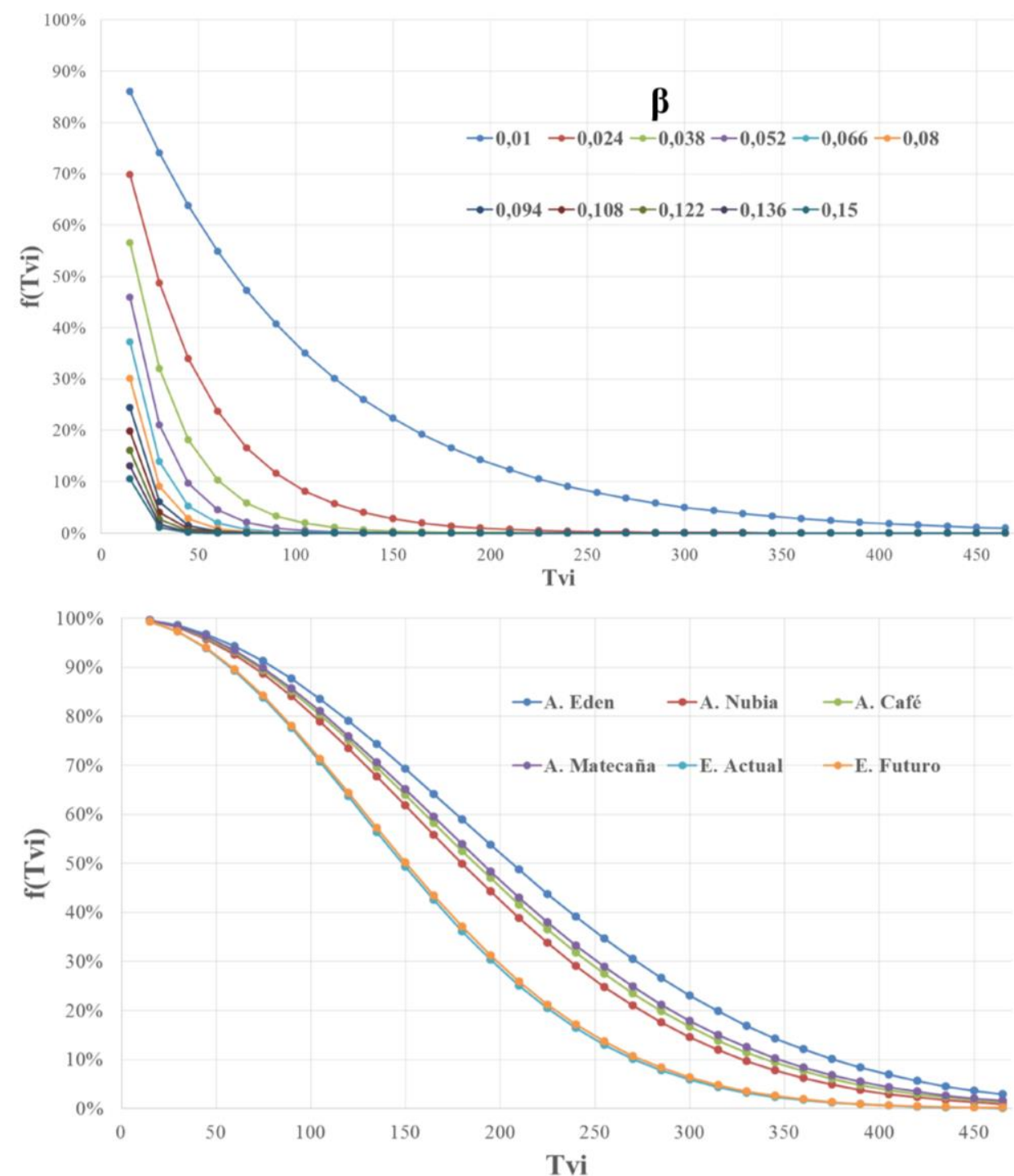

Figure 8. Decay functions. Distance decay function (top). Modified Gaussian function (bottom)

Table 4. Potential accessibility with distance decay function and modified Gaussian decay function

\begin{tabular}{|c|r|r|r|r|c|c|}
\cline { 2 - 8 } & Coffee Airport & Eden Airport & Matecaña Airport & La Nubia Airport & Current Scenario & Future Scenario \\
\hline $\begin{array}{c}\text { Potential accessibility with } \\
\text { distance decay function }\end{array}$ & $40.72 \%$ & $38.07 \%$ & $46.13 \%$ & $35.03 \%$ & $57.35 \%$ & $58.31 \%$ \\
\hline $\begin{array}{c}\text { Potential accessibility with } \\
\text { modified Gaussian decay function }\end{array}$ & $88.38 \%$ & $80.61 \%$ & $89.85 \%$ & $80.41 \%$ & $92.57 \%$ & $93.35 \%$ \\
\hline
\end{tabular}

Because the decrease in the modified Gaussian function is slightly close to the origin, it generates higher potential accessibility in different scenarios. Despite this, the trend appreciated in table 4 continues, where the future scenario of analysis grows less than $1 \%$ by the start-up of the Coffee Airport. Also, the Matecaña Airport holds the equipment that best covers the PITCCLs, given its location in the region, reaching a value of $89.846 \%$ close to that recorded by the coverage of all airports $(92.5654 \%)$. In this same scenario is the Coffee Airport with $88.3799 \%$, indicating that in terms of potential accessibility could generate adequate coverage to the entire CCL region. On a third line, are the airports' El Edén and La Nubia, which have values close to $80 \%$, lower than those registered by the Matecaña and by the Coffee Airport, which indicates that their location is not suitable for the boost of the PITPCCs.

\section{CONCLUSION}

This methodological proposal quantifies the added value that the location of a new airport in a specific region can generate population coverage and touristic points of interest. Likewise, the methodology has the virtue of being able to be replicated and adapted in different contexts by obtaining the necessary layers for its calculation (road network, facilities to analyse, population, and touristic points to measure). Besides, this methodology can be adapted to measure the current coverage that offers airports or transportation terminals towards touristic points in order to take action in infrastructure projects and the touristic points location to generate an impulse in tourism through order planning. In this case study, it was found that the proposed new airport infrastructure work (Coffee Airport) is a transport infrastructure project of utmost importance to the CCL region and that it has the ability to become an articulating axis for the impulse of the CCL tourism because it would reduce the travel time to access to and from the airports to about 480 thousand inhabitants in the departments of Caldas and Risaralda, representing just over $16 \%$ of the inhabitants in the studied area. Besides, Coffee airport construction will boost the development of the Palestina municipality.

Through saving gradient differences in travel time generated by the construction of Coffee airport was measured, generating savings to a huge percentage of the population. Despite this, some municipalities in the study zone (like north of Caldas department) have difficult 
accessibility because of high travel times towards airports. This generates less probability to use air transport to travel to other parts of the country. Besides, from the tourist point of view, high travel times generate less probability to access for tourists, and generated a decrease in the tourist points demand of the study zone. In these case, two kinds of politics should be boost (We recommend them complement each other): Firstly, the improvement of the regional road infrastructure network should be carried out, with the objective of decrease the travel times and to increase the accessibility towards airports. Secondly, the region should generate touristic packages with attractive touristic points in the most remote zones from airports with the objective that touristic arrives at airports in the zone have a concrete supply to access.

Also, in terms of potential accessibility, the Coffee Airport generates improvements of just over 1\% in coverage to PITPCCs, indicating that from the point of view of the location of airport infrastructure and touristic equipment, the Coffee Airport generates a minimal benefit compared to the current situation of operation of airports in the region. On the other hand, the Coffee Airport compared to the airport La Nubia, provides greater potential access to the PITCCLs, suggesting that the bet that it replaces the latter in its entirety as Caldas Airport is a wise decision, in addition, that the operations of the Coffee Airport will include international cargo and passenger traffic. To boost the CCL and their tourism is necessary a strong relationship between regional governments and airlines in order to create new routes and tourism facilities like the Coffee Airport, among others. On the other hand, the decay functions used yielded different results in the regional analysis due to the form they take. In the case of the distance decay function, which depends on the deterrence factor, it decays more quickly close to the origin, so in the analysis at the regional level where the travel time is greater than in urban analysis, the probability of travel decreases as travel time grows. In the case of the modified Gaussian function, which depends on travel time vector dis persion factors, it decays in a slightly way near the origin generating behaviour that allows analysis with high travel times, being the highest potential accessibility, so this function is suitable for analysis at the region level, where travel times reach high values, while the negative exponential function works best in the urban analysis where travel times are low compared to region-level analysis. In addition, the modified Gaussian function is calibrated with the data obtained from travel time, meanwhile, the negative exponential function uses the deterrence factor that is calculated by target source data from the studied area, which were not available in this case study .

Therefore, the modified Gaussian function is performed in an acceptable way for studies where reliable destination source data is not accessible and where travel time reaches high values as in regional analyses presented in this research.

The sensibility curve constructed with Beta parameters between 0.15 and 0.01 , helped to choose the correct Beta parameter for the study in the decay function, finding an inversely proportional tendency, while the Beta parameter increases, probability to travel decreases. This tendency dramatically rises because of high travel time values on the regional scale of the rese arch. Besides, a low Beta parameter, like the chosen one in the potential accessibility analysis for the study case implies a high willingness to travel towards tourism facilities, this is a good approximation for the kind of travel that tourism is.

Integral accessibility is a powerful tool in that it can quantify the coverage of population and tourist points through the calculation of travel time and the construction of the isochronous curves, at the same time, these two measures are intake for the calculation of potential accessibility so in this methodology both accessibility measures are complementary. Besides, integral accessibility is an adaptable tool because of researchers could use a different kind of facilities to measure the coverage of tourism in a region. This methodology has some limitations in the calculation of the distance decay functions that could be improved using the origin-destination matrix. However, CCL does not exist this kind of mobility study consequently in future research and governmental studies its measure could be boosted in order to make decisions supported in its results. Besides, in this methodology, the private vehicle was considered, in future research, public transport, and its supply could be considered in order to promote their use of within to tourist and region inhabitants.

\section{Acknowledgement}

The researchers thank the Universidad Nacional de Colombia and the members of the Sustainable Mobility Research Group (GIMS), especially Daniel Gonzales Nuñez and María del Mar Rodas Zuleta for their support in the document, the Ministry of Culture of Colombia and Julian Marin for the support in the translation and edition of the manuscript. Thanks to the reviewers who with their suggestions have contributed to the ostensible improvement of the full paper.

\section{REFERENCES}

Caldwell, T. (1961). On Finding Minimum Routes in a Network With Turn Penalties. Communications of the ACM, 4(2), 107-108. https://doi.org/10. $1145 / 366105.366184$

Cárdenas Martínez, M.P., \& Buitrago Márquez, I.A. (2016). Benchmarking de turismo sostenible para el paisaje cultural cafetero de Colombia [Benchmarking sustainable tourism for Colombia's cultural coffee landscape], 23-48. [online] Available at: https://dialnet.unirioja.es/servlet/articulo?codigo=7337172

Cardona, S. (2018). Propuesta metodológica para el cálculo de las penalidades por giro en modelos de accesibilidad [Methodological proposal for the calculation of rotation penalties in accessibility models], Master's dissertation, Universidad Nacional de Colombia, Manizales, Colombia. [online] Available at: http://bdigital.unal.edu.co/70189/

Cardona, S., Escobar, D.A., \& Moncada, C.A. (2018). Análisis de Accesibilidad como Herramienta para la Generación de Zonas Libres de Tráfico. Caso del Municipio de La Dorada en Colombia [Accessibility analysis as a tool for the generation of traffic free zones. Case study: La Dorada, Colombia. Información Tecnológica, 29(5), 203-214. (in Spanish). http://dx.doi.org/10.4067/S0718-07642018000500203

Chun, Y., \& Griffith, D.A. (2013). Spatial Statistics and Geostatistics. In Sage. SAGE Publications.

Dijkstra, E.W. (1959). A note on two problems in connexion with graphs. Numerical Mathematics, 1(1), 269-271. https://doi.org/10.1007/BF01386390

Duval, D.T. (2013). Critical Issues in Air Transport and Tourism. Tourism Geographies, 15(3), 494-510. https://doi.org/10.1080/14616688.2012.675581

Echenique, M., Crowther, D., \& Lindsay, W. (1969). A Spatial Model of Urban Stock and Activity. Regional Studies, 3(3), 281-312. https://doi.org/10.1080/09595236900185291

Escobar, D.A., Cardona, S., \& Moncada, C.A. (2019). Alcance Geoespacial de Atención del Cuerpo de Bomberos . El Caso del Municipio de Manizales en Colombia [Geospatial Extent of a Fire Department Attention. The Case of the Municipality of Manizales in Colombia]. Información Tecnologica, 30(5), 283-290 (in Spanish). http://dx.doi.org/10.4067/S0718-07642019000500283

Escobar, D.A., Tapasco, O., \& Giraldo, J.A. (2015). Medición de Desempeño del Sistema de Transporte Cable Aéreo de la Ciudad de Manizales en Colombia, usando Tres Enfoques: Analítico, Simulado y de Accesibilidad Urbana [Measuring of the Performance of the Overhead Cable Transport System of the City of Manizales in Colombia, using Three Approaches: Analytical, Simulated and Urban Accessibility]. Informacion Tecnologica, 26(6), 199-210 (in Spanish). http://dx.doi.org/10.4067/S0718-07642015000600020

Eva, M., \& Iatu, C. (2015). Modelling spatial accessibility to medical care. Case study of the north-eastern region of Romania. Human Geographies, 9(2), 151-164. http://dx.doi.org/10.5719/hgeo.2015.92.3

Geurs, K.T., \& Ritsema van Eck, J.R. (2001). Accessibility measures: review and applications. Evaluation of accessibility impacts of land-use transportation scenarios, and related social and economic impact. RIVM rapport 408505006. [online] Available at: https://www.pbl.nl/en/publications/ Accessibility_measures_review_and_applications 
Halás, M., Klapka, P., \& Kladivo, P. (2014). Distance-decay functions for daily travel-to-work flows. Journal of Transport Geography, 35, 107-119. https:// doi.org/10.1016/j.jtrangeo.2014.02.001

Hansen, W.G. (1959). How Accessibility Shapes Land Use. Journal of the American Planning Association, 25(2), 73-76. https://doi.org/10. $1080 / 01944365908978307$

Harb, G., \& Bassil, C. (2020). Gravity analysis of tourism flows and the 'multilateral resistance to tourism.' Current Issues in Tourism, 23(6), 666-678. https://doi.org/10.1080/13683500.2018.1544612

Holguin, J.M., Escobar, D.A., \& Moncada, C.A. (2018). Access to Emergency Medical Services: An Urban Planning Methodology for the Generation of Equity. Global Journal of Health Science, 10(6), 181-198. https://doi.org/10.5539/gjhs.v10n6p181

Ingram, D.R. (1971). The Concept of Accessibility: A search for an operational form. Regional Studies, 5(2), 101-107. https://doi.org/10.1080/09595237100185131

Kozyrev, V.P. (1972). Graph Theory. Journal of Soviet Mathematics, 2, 489-519. https://doi.org/10.1007/BF01085015

Lohmann, G., \& Vianna, C. (2016). Air route suspension: The role of stakeholder engagement and aviation and non-aviation factors. Journal of Air Transport Management, 53, 199-210. https://doi.org/10.1016/j.jairtraman.2016.03.007

Martínez, L.M., \& Viegas, J.M. (2013). A new approach to modelling distance-decay functions for accessibility assessment in transport studies. Journal of Transport Geography, 26, 87-96. https://doi.org/10.1016/j.jtrangeo.2012.08.018

Miller, E.J. (2018). Accessibility: measurement and application in transportation planning. Transport Reviews, 38(5), 551-555. https://doi.org/ $10.1080 / 01441647.2018 .1492778$

Olariaga, D., Rodríguez, L., \& Ligia, A. (2016). Comportamiento E Interrelación Del Turismo Y El Transporte Aéreo En Colombia [Behavior And Interrelationship Of Tourism And Air Transport In Colombia. Estudios y Perspectivas En Turismo, 25(1), 36-56 (in Spanish).

Olsson, M. (2016). Functional regions in gravity models and accessibility measures. Moravian Geographical Reports, 24(2), 60-70. https://doi.org/ 10.1515/mgr-2016-0011

Paulino, I., Prats, L., \& Whalley, P.A. (2019). Establishing Influence Areas of Attractions in Rural Destinations. Tourism Planning and Development, 1-25. https://doi.org/ 10.1080/21568316.2019.1673811

Ramírez Arias, S., \& Saldarriaga Ramírez, C. (2014). Usos y abusos del paisaje cultural cafetero: una reflexión desde el concepto de patrimonio [Uses and abuses of the cultural landscape of coffee: a reflection from the concept of heritage]. Jangwa Pana, 12(1), 115-128 (in Spanish). https://doi.org/10.21676/16574923.776

Reynolds-Feighan, A., \& McLay, P. (2006). Accessibility and attractiveness of European airports: A simple small community perspective. Journal of Air Transport Management, 12(6), 313-323. https://doi.org/10.1016/j.jairtraman.2006.07.009

Rodrigue, J.P., Comtois, C., \& Slack, B. (2013). The geography of transport systems. In Routledge (third edition )

Salze, P., Banos, A., Oppert, J. M., Charreire, H., Casey, R., Simon, C., Chaix, B., Badariotti, D., \& Weber, C. (2011). Estimating spatial accessibility to facilities on the regional scale: An extended commuting-based interaction potential model. International Journal of Health Geographics, $10(2), 1-16$. https://doi.org/10.1186/1476-072X-10-2

Seguí, J.M., \& Petrus, J.M. (1991). Geografía de Redes y Sistemas de Transporte [Geography of Transport Networks and Systems]. Madrid: Sintesis. (in Spanish).

Sharpley, R. (2008). Planning for tourism: The case of Dubai. Tourism and Hospitality, Planning and Development, 5(1), 13-30. https://doi.org/ $10.1080 / 14790530801936429$

B., Lohmann, G., \& Scott, N. (2018). Air transport and tourism-a systematic literature review (2000-2014). Current Issues in Tourism, 21(9), 975-997. https://doi.org/10.1080/13683500.2017.1334762

Taylor, P.J. (1975). Distance decay in spatial interactions. Concepts and Techniques in Modern Geography, 2, 1-35.

Vale, D.S., \& Pereira, M. (2016). The influence of the impedance function on gravity-based pedestrian accessibility measures: A comparative analysis. Environment and Planning B: Urban Analytics and City Science, 44(4), 740-763. https://doi.org/10.1177/0265813516641685

Xi, Y. (Luna), Miller, E.J., \& Saxe, S. (2018). Exploring the Impact of Different Cut-off Times on Isochrone Measurements of Accessibility. Transportation Research Record: Journal of the Transportation Research Board., 1-12. https://doi.org/10.1177/0361198118783113

Xiao, N. (2016). GIS Algorithms: Theory and Applications for Geographic Information Science \& Technology. In GIS Algorithms: Theory and Applications for Geographic Information Science \& Technology. In Sage. SAGE Publications. http://dx.doi.org/10.4135/9781473921498

Yiannakoulias, N., Bland, W., \& Svenson, L.W. (2013). Estimating the effect of turn penalties and traffic congestion on measuring spatial accessibility to primary health care. Applied Geography, 39, 172-182. https://doi.org/10.1016/j.apgeog.2012.12.003

Zhang, D., \& Wang, X.C. (2014). Transit ridership estimation with network Kriging: A case study of Second Avenue Subway, NYC. Journal of Transport Geography, 41, 107-115. https://doi.org/10.1016/j.jtrangeo.2014.08.021

Zuluaga, J., \& Escobar, D. (2017). Análisis de accesibilidad territorial de la región noroccidente de Colombia [Analysis of territorial accessibility of the northwestern region of Colombia]. Revista Espacios, 38(6), 30-45. (in Spanish). [online] Available at: https://www.revistaespacios.com/a17v38n06 /a17v38n06p30.pdf

*** Civil Aeronautics of Colombia. (2019). Estadisticas de las actividades aeronauticas [Statistics on aeronautical activities]. [online] Available at: www. aerocivil.gov.co > atencion > estadisticas-de-las-actividades-aeronauticas. (in Spanish).

*** Coffee Airport. (2017). Aeropuerto del Café: creando oportunidades [Coffee Airport: creating opportunities.]. [online] Available at: http://www. aeropuertodelcafe.com.co/media/PDF/presentacioningles.pdf [Accessed 8 Nov. 2019]. (in Spanish).

*** Coffee Airport. (2019). Reseña Histórica - Aeropuerto del Café [Historical Review - Coffee Airport]. [online] Available at: http://site. aeropuertodelcafe.com.co/resena-historica/ [Accessed 12 Nov. 2019]. (in Spanish).

*** Consejo Nacional de Política Económica y Social (Conpes), Republica de Colombia. (2004). Garantía de la nación a Inficaldas e Infimanizales, para contratar operaciones de crédito publico externo con el gobierno español a través del instituto de crédito oficial - ICO- hasta por US\$20 millones, , destinados a la financiación parcial del proyecto "construcción del aeropuerto de Palestina" [National guarantee to Inficaldas and Infimanizales, to contract external public credit operations with the Spanish government through the official credit institute - ICO - for up to US\$20 million, for the partial financing of the project "construction of the airport in Palestine"]. (in Spanish).

*** Consejo Nacional de Política Económica y Social (Conpes), Republica de Colombia. (2009). Importancia estratégica del proyecto "Aeropuerto del Café" [Strategic importance of the "Coffee Airport" project]. (in Spanish).

*** National Administrative Department of Statistics (DANE). (2019). Resultados censo nacional de población y vivienda 2018. Colombia.

*** New Zeland Transport Agency. (2013). The New Zealand accessibility analysis methodology. Retrieved from http://www.nzta.govt.nz/resources/ research/reports/512/\%0Ahttps://trid.trb.org/view/1249198

*** Matecaña Airport. (2019). Red de Rutas - AIM [Route network - AIM]. [online] Available at: http://aeromate.gov.co/viajeros/red-de-rutas/ [Accessed 10 Nov. 2019]. (in Spanish).

*** Tourist information system of the Coffee Cultural Landscape (SITURCCL). (2019). Indicadores | SITUR CCL. [online] Available at: http://siturCCL.com/ indicadores-CCL/?indicador=mapa [Accessed 1 Sep. 2019].

*** UNESCO. (2011). Cofee Cultural Landscape: An exception fusion of nature, collective human effort and culture.

*** UNWTO. (2019). International Tourism Highlights International tourism continues to outpace the global economy. 1-24.

*** World Bank (2019). Transporte aéreo, pasajeros transportados | Data. [Online] Available at: https://datos.bancomundial.org/indicador/IS.AIR.PSGR? end=2018\&start=1970\&type=shaded \&view=chart [Accessed 16 Nov. 2019]. 